\title{
Hepatitis A outbreak in British Columbia, Canada: the roles of established surveillance, consumer loyalty cards and collaboration, February to May 2012
}

\author{
H M Swinkels (helena.swinkels@fraserhealth.ca) ${ }^{1,2}, M$ Kuo 3 , G Embree ${ }^{4}$, Fraser Health Environmental Health Investigation \\ Team 5 , A Andonov ${ }^{6}$, B Henry ${ }^{2,3}$, J A Buxton ${ }^{2,3}$ \\ 1. Office of the Medical Health Officer, Public Health Fraser Health Authority, Surrey, Canada \\ 2. School of Population and Public Health, University of British Columbia, Vancouver, Canada \\ 3. Communicable Disease Prevention and Control Services, British Columbia Centre for Disease Control, Vancouver, Canada \\ 4. Health Protection, Public Health, Fraser Health Authority, Surrey, Canada \\ 5. The team members are listed at the end of the article \\ 6. National Medical Laboratory, Canadian Science Centre for Human and Animal Health, Public Health Agency of Canada, \\ Winnipeg, Canada
}

Citation style for this article:

Swinkels HM, Kuo M, Embree G, Fraser Health Environmental Health Investigation Team, Andonov A, Henry B, Buxton JA. Hepatitis A outbreak in British Columbia, Canada: the roles of established surveillance, consumer loyalty cards and collaboration, February to May 2012. Euro Surveill. 2014;19(18):pii=20792. Available online: http://www.eurosurveillance.org/ViewArticle.aspx?Articleld $=20792$

Article submitted on 02 July 2013 / published on 08 May 2014

Non-travel-related hepatitis $A$ is rare in Canada. We describe a hepatitis A outbreak investigation in British Columbia in February to May 2012 in which exposure history was collected from nine confirmed non-travelrelated cases. Suspected foods were tested for hepatitis A virus (HAV): a frozen fruit blend was identified as a common exposure for six of the nine cases using supermarket loyalty cards. Consumption of the product was confirmed in each case. Genetic analysis confirmed HAV genotype $1 \mathrm{~B}$ in the six exposed cases. Of the three non-exposed cases, the virus could not be genotyped for two of them; the virus from the other case was found to be genotype $1 \mathrm{~A}$ and this case was therefore not considered part of the outbreak. HAV was detected by PCR from pomegranate seeds, a component of the identified frozen fruit blend. Historically low levels of HAV infection in British Columbia triggered early recognition of the outbreak. Loyalty card histories facilitated product identification and a traceback investigation implicated imported pomegranate seeds.

\section{Background}

The annual number of reported cases of hepatitis $A$ have consistently decreased in the past decade in British Columbia (BC), Canada, due to improved standards of hygiene and sanitation and provincially funded hepatitis A immunisation for high-risk groups, including people with chronic liver disease, chronic hepatitis $B$ and $C$, people who inject drugs and men who have sex with men [1] and post-exposure prophylaxis [2]. in 2010-2011, 30 out of 45 cases reported in BC, were related to travel to countries where hepatitis $A$ remains endemic [3].

Hepatitis A virus (HAV) is primarily spread by the faecal-oral route, either through direct contact or through ingestion of contaminated food or water. The incubation period is $15-50$ days. Some infected persons have mild or no symptoms, while others may experience moderate to severe symptoms over weeks or months including fever, dark urine, loss of appetite, malaise, vomiting, pale stools, abdominal pain and/or jaundice [4].

Outbreaks may occur as a result of a food handler at a food establishment being infected; widespread foodborne outbreaks have been associated with uncooked or fresh food contaminated before distribution $[5,6]$. Epidemiological evidence (supported by identical molecular sequences among the cases) has implicated a variety of foods in outbreaks, for example, green onions, semi-dried tomatoes, blueberries and frozen strawberries [5,7-11]. Laboratory confirmation of HAV contamination of vegetables and fruit is rare, in part due to low viral loads in many foods $[12,13]$. Molecular subtyping has improved the ability to detect outbreaks caused by HAV [14].

In 2012, an investigation was launched following the identification of three non-travel-related hepatitis $A$ cases within one week in one of BC's five geographically based health authorities, compared with 10 hepatitis A cases in the affected HA in the previous year, six of which were related to travel to endemic countries [3]. This paper describes the investigation of the outbreak which, despite its small size, was rapidly epidemiologically linked to a specific food product. Although genotypic matching to the cases was not possible, HAV was subsequently confirmed in a component of the implicated product. 


\section{Methods}

\section{Outbreak case definition}

The initial outbreak case definition included residents of BC who had laboratory-confirmed acute HAV infection (IgM antibodies to HAV and acute illness with discrete onset of compatible symptoms and jaundice or elevated serum aminotransferase levels, in the absence of recent HAV vaccination) since 1 January 2012 AND no history of travel to an HAV-endemic country in the 50 days before onset of symptoms. The case definition was modified as additional laboratory and exposure data became available. The final case definition (used in this paper) was established in the seventh week of the outbreak and included a possible case (laboratory-confirmed non-travel-related HAV infection) and a confirmed case (HAV genotype 1B with matching sequencing results).

\section{Sample collection and testing}

Sera were screened for anti-HAV IgM by Siemens Advia Centaur HAV IgM (Siemens, Canada) and if positive, the result was confirmed on a second platform, Abbott Architect HAV IgM (Abbott, Canada). Dual enzyme immunoassay IgM samples were sent for HAV genotyping to the National Microbiological Laboratory in Winnipeg, Manitoba. HAV RNA was amplified by nested $P C R$ using primers targeting the VP1-2A junction of the HAV genome (F1, 50-GAC AGA TTC TAC ATT TGG ATT GGT-3', 2,870-2,894; R1 50-CCA TTT CAA GAG TCC ACA CAC T-30, 3,382-3,360; F2, 50-CTA TTC AGA TTG CAA

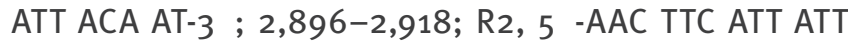
TCA TGC TCC T-3 $\square, 3,189-3,169$ ). Primers were based on GenBank accession number M14707 HAV wild type. Amplicons were sequenced on an $A B 373 \mathrm{XL}$ genetic analyzer (Applied Biosystems) using BigDye v.3.1 Terminator chemistry. MEGA 5.2.1 software version was used to determine the best-fit nucleotide substitution model for the current HAV sequences. Maximum Likelihood analysis was done by the recommended Tamura-Nei distance model using the discrete gamma distribution with default rate category $5(+\mathrm{G})$ and modeled for invariant sites (+l) [15]. Meaningful taxonomic relationships were obtained by bootstrap resampling analysis (200 replicates).

\section{Investigation of possible source}

A provincially standardised questionnaire, focusing on common food shopping and dining experiences, was administered by telephone to cases. Case follow-up included evaluation of household and other contacts for symptoms and assessing the need for post-exposure prophylaxis. Based on an initial hypothesis that the common agent was a food product distributed only within the affected region, an enhanced questionnaire was then administered, again by telephone, further exploring locally produced and distributed food items.

In addition, authorisation was obtained from cases who shopped at major supermarket chains for those chains to release detailed shopping histories via the

\section{FIGURE 1}

Location of non-travel-related hepatitis A cases reported to public health authorities, British Columbia, Canada, February-May 2012 (n=9)

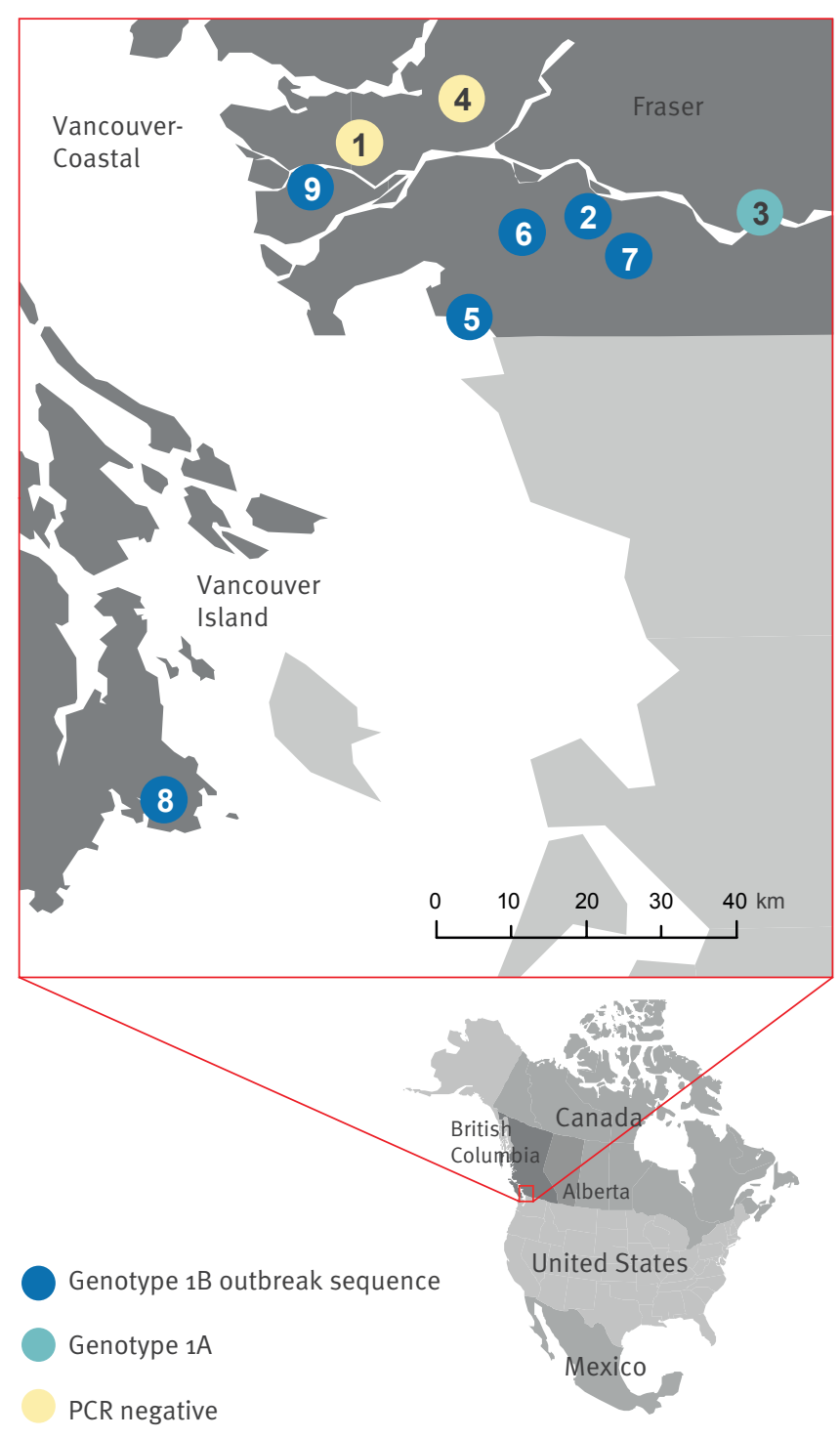

The dots are oversized and represent the approximate place of residence of cases. They are offset by up to $500 \mathrm{~m}$ to avoid identification of the cases. The cases are numbered in order of the dates in which they were reported to the local public health authority. The first seven were reported in Fraser Health Authority, followed by one each in Vancouver Island (Case 8) [29] and Vancouver Coastal Health Authorities (Case 9).

cases' store loyalty cards. Shopping histories going back three months were analysed to include products with an extended refrigerated or frozen storage life.

An investigation of the plant that produced the implicated food product included a review of shipping and purchase invoices, bills of lading (a legal document describing the merchandise in a shipment, confirming ownership and identifying the recipient), sources of ingredients and production records to determine 
Timeline of non-travel-related hepatitis A cases reported to public health authorities, British Columbia, Canada, February-May 2012

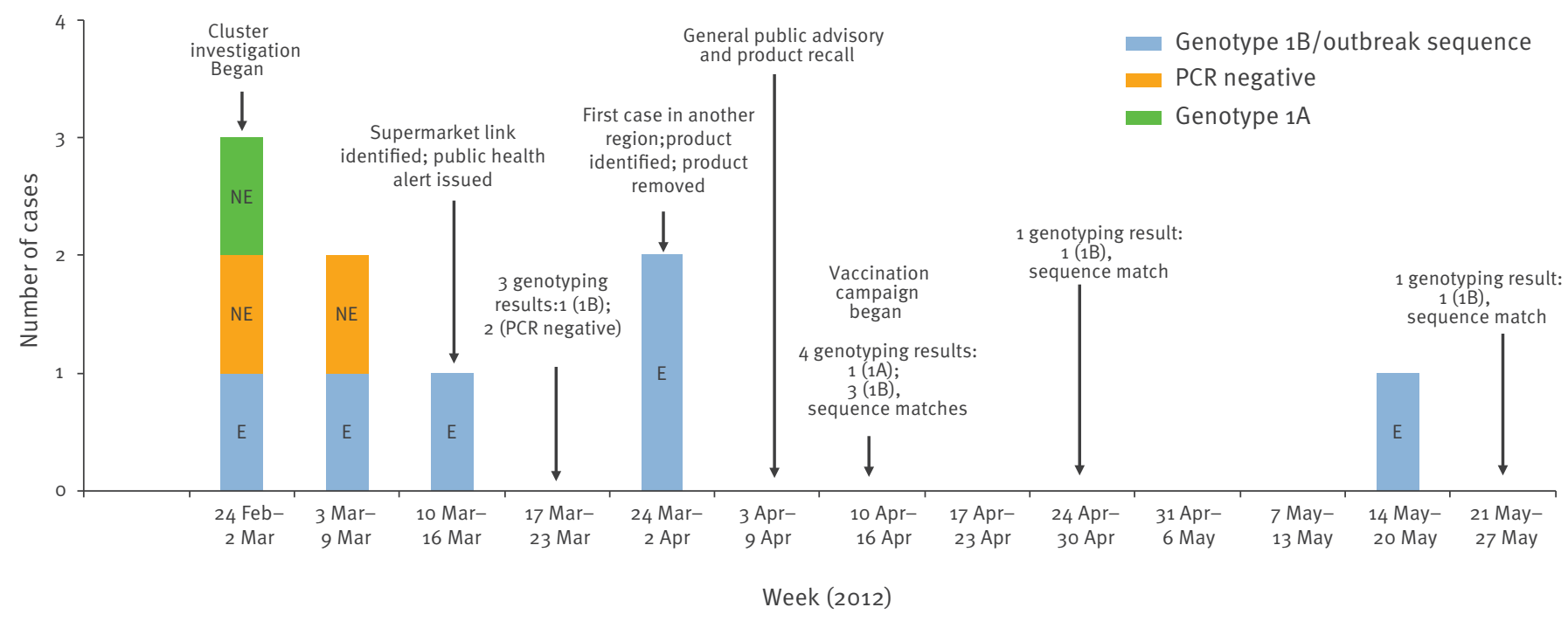

E: exposed; NE: not exposed.

production dates, worker travel and illness histories and distribution details of the product.

Several packages of the implicated product were tested: one open and one closed package from homes of two of the cases and a composite of five packaged units of the product obtained from the production facility. Samples of three of the four individual ingredients of the product from the manufacturer were available and tested for HAV by the Canadian Food Inspection Agency. Testing of implicated food products was conducted using magnetic cationic beads to capture and concentrate the viruses. Extracted viral RNA was subjected to a reverse-transcription PCR assay for HAV detection and quantification by real-time PCR.

\section{Results}

Detection of the outbreak

The investigation was triggered during the first week of March 2012, when three non-travel-related hepatitis A cases (Cases 1-3), residing in three different municipalities in BC located in one health authority, were identified within a week, based on laboratory reports to the local public health authority and subsequent public health follow-up (Figure 1). Three more cases (Cases 4-6) from three more municipalities in the same health authority were identified in the following two weeks (Figures 1 and 2). A further two cases (Cases 7 and 8) were identified later in March and a final case (Case 9) in May.

During this investigation, there were a total of nine possible outbreak cases (laboratory-confirmed HAV infection with no travel history). Symptoms included fever, nausea, abdominal pain, diarrhoea and jaundice; the onset dates ranged from the second week of February to the last week of April 2012. Dates of laboratory reports to the public health authorities ranged from the fourth week of February to the second week of May. Two cases were hospitalised.

Of the nine possible cases, six reported consumption of a frozen fruit blend; three did not. Analysis of the initial standard and enhanced questionnaire from these cases did not reveal any common activities, food purchases or consumption history above what would be expected for the general public.

\section{Identifying the implicated food product}

Food purchase histories obtained from the initial six possible cases showed that the majority $(n=5)$ had shopped for groceries at a major chain of affiliated supermarkets. Analysis of loyalty card use indicated that three of the six cases had purchased the same frozen fruit blend at that retail chain. Consumption or not of the product was confirmed by interview for all six cases.

The outbreak team asked the chain to provide further details on production and distribution of this product in the third week of March 2012. It was a blend of raw frozen fruit (blueberries, strawberries, dark cherries and pomegranate seeds) in a $600 \mathrm{~g}$ package produced under a private house label for the supermarket chain and distributed to their stores in $B C$ and the neighbouring province of Alberta. Multiple lot codes had been purchased by the cases. The chain 
described the product as relatively uncommon, with sales of approximately 56,000 units of the product to 31,000 households throughout the two provinces during the four months before the query. With an average household size of 2.5 [16] and a total population of 8 million [17], approximately $1 \%$ of the population in the two provinces would have lived in households that had purchased the product.

\section{Detection of further cases}

By the end of March, a further two cases of hepatitis $A$ who had consumed the frozen fruit blend were reported (Figure 1): one in the same health authority as the previous cases (Case 7) and the other, a food service worker, in another health authority (Case 8). Although only one genotype result was available at this time, based on the epidemiological information from cases and a product risk assessment conducted by the $\mathrm{BC}$ Centre for Disease Control in collaboration with the health authority in which the majority of cases occurred, a general public health advisory was issued on 5 April 2012 by the BC Centre for Disease Control [18]. This advisory included information that the product was available for sale or could be in the consumers' homes. Later the same day, the Canadian Food Inspection Agency also issued a Class I (high risk) Health Hazard Alert recalling the product $[19,20]$. This indicates a high risk that eating or drinking the product can lead to serious health problems $[19,21]$. This was triggered by a health risk assessment conducted by Health Canada consistent with weight of evidence standards [21] and based on the epidemiological information provided and collated by the health authorities and the BC Centre for Disease Control [20].

A final non-travel-related hepatitis A case (Case 9), who confirmed consumption of the implicated product, was identified in another health authority six weeks after the product recall, bringing the total number of possible outbreak cases to nine, six with the exposure and three without the exposure.

The six exposed cases were classed as confirmed outbreak cases, as they were found to be infected with HAV genotype $1 B$ with matching genetic sequences. The sequence of the first identified case $\left(\mathrm{H}_{12}\right.$-1327) used as a reference sequence for the outbreak has the GenBank accession number KF947077. Three of the six confirmed cases were male and three female. The median age was 32 years (range: 19-49).

Of the three non-exposed cases, the virus could not be genotyped for two of them; the virus from the third case was found to be genotype $1 \mathrm{~A}$ and was therefore excluded as an outbreak case. There were no secondary cases. The outbreak strain was compared with available HAV strains from the United States (US) as well as some European strains in GenBank available at that time and was found to be unique (Figure 3).
FIGURE 3

Phylogenetic tree derived from sequences of the VP1-P2A junction of the hepatitis A virus genome of the 2012 British Columbia, Canada, outbreak strain and reference strains

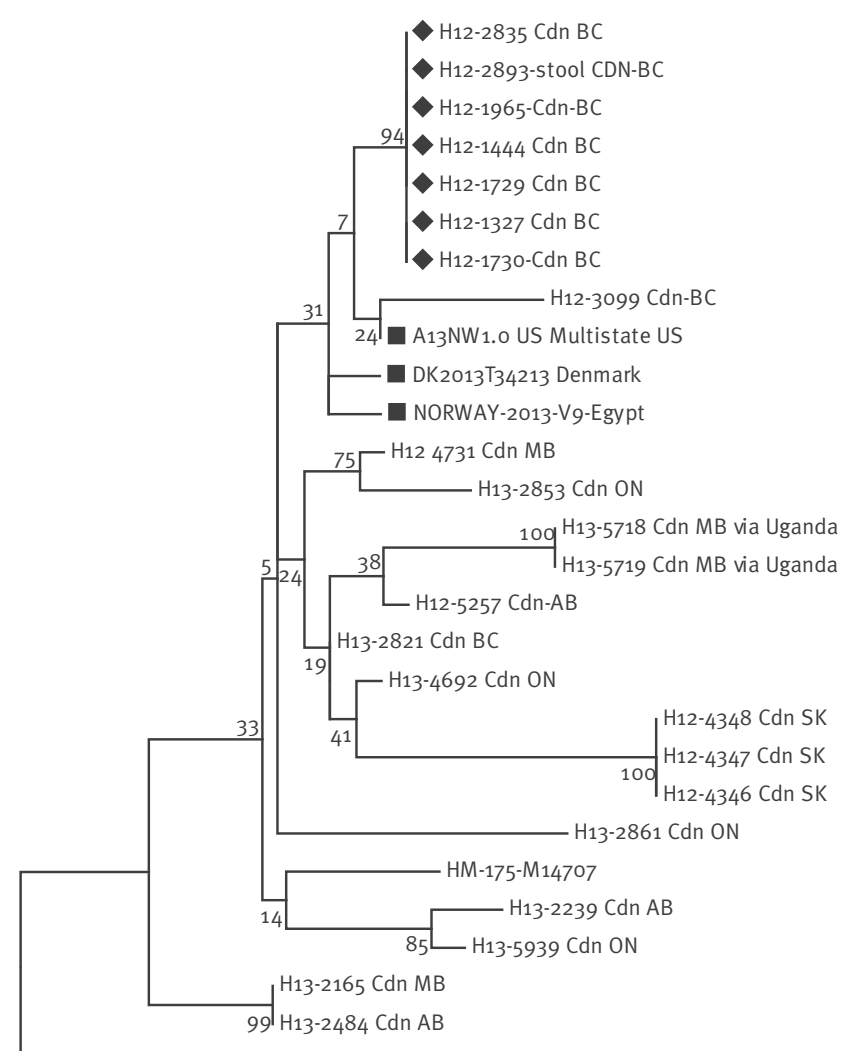
686-04-Cdn-ON-373 0.01

HAV: hepatitis A virus.

Neighbour-joining phylogenetic tree showing the relationship between the British Columbia HAV outbreak strain with reference HAV strains (recent European and US HAV $1 B$ sequences from GenBank and all Canadian genotype 1B samples from 2012 to 2013). Note that the stool sample $\mathrm{H}_{12}-2893$ and serum sample $\mathrm{H}_{12-2835}$ are from the same patient. HAV genotype $1 \mathrm{~A}$ sequence (686-04-CDN-ON-373) located at the bottom of the tree is included as an outlier.

- British Columbia, Canada, HAV outbreak strain

- Reference HAV strains

\section{Public health measures}

A general post-exposure immunisation campaign was initiated in April 2012 for individuals who had consumed the frozen fruit blend within two weeks, with a targeted campaign directed to customers potentially exposed to the virus through the case who worked at a food establishment (Case 8). These vaccinations were offered through the local public health authorities and communicated through news releases to media channels.

The plant that produced the frozen fruit blend was a federally registered facility located in the same region of $B C$ as the majority of possible cases and subject to 
regular inspection. Incoming products at the plant were routinely screened for bacterial contamination but not for viral pathogens. Investigation revealed the blueberries and strawberries in the implicated product were also used in a variety of other frozen products sold by several retailers under multiple brand names. The frozen fruit blend was the only one produced at the facility that contained cherries or pomegranate seeds. The cherries were imported from a supplier in Washington State in the US and the country of origin was not identified. The last shipment was received about four months before symptom onset of the first case. A shipment of pomegranate seeds used in the product was received 11 months before the outbreak from a supplier in Egypt. Records indicated that the Egyptian supplier had made only this single shipment to Canada in the previous year. These pomegranate seeds were used briefly upon arrival and then a switch was made to a US product. Use of the Egyptian product resumed when the US product ran out six months before the outbreak.

The investigation confirmed that the plant had a written staff illness policy requiring all ill staff to be off work (in context of food safety, illness was defined as gastrointestinal illness or any other illness that impedes the maintenance of good personal hygiene, such as respiratory illness). No staff illness relevant to food safety was reported in the 50 days before a site visit to investigate the outbreak in the first week of April. However, some of the workers at the manufacturing facility had a history of recent travel to HAVendemic areas. Use of gloves, hairnets and gowns was mandated for production area staff and hand hygiene stations were readily available. Direct handto-product contact during packaging occurred only to remove unacceptable or poor-quality products from the packaging line. There was no HAV vaccination programme for workers but the hygiene conditions, procedures and processes observed during investigation were assessed as adequate to minimise the risk of HAV transmission from a potentially infected worker to food products.

Workers typically packaged multiple products for various clients on any given day. The suspect frozen fruit blend was produced to order for the supermarket chain. Each product order, estimated to be about two weeks apart, would take about two hours to package. The product was then sent to the chain's distribution warehouse, from where in turn it was distributed to their stores. The retailer voluntarily removed remaining stock of the product from sale, without public notification, the day before it was recalled, when they became aware from investigators that the product was under increased scrutiny as a possible source of this outbreak.

HAV was not identified in any packaged samples but was confirmed by PCR in one lot of pomegranate seeds obtained from the manufacturer of the frozen fruit blend; however, genotype analysis was not successful.

\section{Discussion}

Some of the largest food-borne outbreaks of hepatitis A in industrialised countries have been traced to produce [5]. As frozen fruit has a long shelf life (up to a year) and HAV has a long incubation period (up to 50 days), outbreaks may be identified only after large numbers of people have been exposed [4]. Outbreaks due to $\mathrm{HAV}$-contaminated frozen fruit have recently been the cause of considerable morbidity: in April 2013, frozen strawberries were implicated in more than 70 cases of HAV infection in four Nordic countries $[22,23]$ and as of 21 June 2013, an outbreak investigation in the US associated with a frozen berry and pomegranate mix confirmed 120 cases of HAV infection in eight states, of whom 54 (45\%) were hospitalised [24].

HAV infection is a reportable communicable disease in $B C$ and cases are routinely reported to the public health authorities. Low background rates of HAV infection, timely identification and reporting and wellcommunicated follow-up protocols that are used routinely in investigating cases of HAV infection in BC allowed early identification of this outbreak. In the previous year, there were 10 hepatitis A cases in the health authority mostly affected, six of whom were related to travel to HAV-endemic countries. Suspicion was raised in $B C$ when three non-travel-related cases were noted in one health authority in one week; in the end, only one of the initial three cases was linked to the outbreak.

Case-control studies are the classical analytical study for food-borne outbreaks. In this outbreak, the weight of epidemiological evidence was deemed sufficient to implicate the frozen fruit as the cause of the outbreak and to trigger a product recall without resorting to an analytical study [21]. The two confirmed cases identified after the recall reported consumption of the frozen fruit blend. Of the three possible outbreak cases in which consumption of the product was not confirmed, one was identified to be infected with HAV genotype $1 \mathrm{~A}$ and the other two remained possible cases as the HAV sequences could not be genotyped.

Published outbreaks of hepatitis $A$ that have identified the virus in a specific product are generally much larger than this outbreak [22,24]. Identification of a specific food source can be difficult in outbreaks because of poor food history recall by cases following the long incubation period and the difficulty identifying HAV in food products. Use of loyalty card data from cases allows a more accurate food purchase history to be obtained than is possible through interviews [25]. Although these data cannot provide information on actual consumption, they can be used to supplement the interviews, to improve recall. Cooperation with the supermarkets was facilitated by well-established local processes [25] for obtaining food purchase histories and good working relationships between the provincial and regional health authorities as well as with the retailers. 
Blends that contain a variety of fruits from a variety of sources are a challenge in terms of identifying a particular component that may be the source. In this outbreak in BC, identification of a specific cause was further complicated by the fact that some of the workers at the manufacturing facility had a history of recent travel to HAV-endemic areas. However, although several different products were manufactured each day at the facility and all the workers worked on multiple production lines, only the frozen fruit blend was implicated in the outbreak. Follow-up by the Canadian Food Inspection Agency determined that the contamination was unlikely to be linked to activities at the federally registered facility where the product was assembled. The investigation then focused on the cherries and pomegranate seeds, which were exclusive to the implicated product: HAV was detected in a sample of the source pomegranate seeds used in the product.

Genotypic confirmation of the virus in the food product could not be obtained, but this is consistent with other outbreaks where HAV sequencing has only occasionally been successful $[10,26]$. Very low viral load in the product may explain our inability to obtain genotypic confirmation and the very low number of cases in the approximately 31,000 potentially exposed households. Although the genotype was not ascertained, we consider that this outbreak was probably due to contamination of the pomegranate seeds. This is consistent with the suggestion of Hida et al. that water quality and handling procedures after harvest may play a role in disease transmission [13]. The geographical distribution of the cases was not consistent with the much broader geographical distribution of the implicated product. This delayed source attribution as the investigation initially considered only locally distributed products. Ultimately, no pattern of production or distribution could explain why most of the outbreak cases were restricted to one health authority within BC.

In Canada, over $90 \%$ of hepatitis A cases from whom the virus is typed are genotype $1 \mathrm{~A}$, with HAV genotype $1 \mathrm{~B}$ making up less than $10 \%$ [27]. Recent outbreaks of hepatitis A associated with frozen fruits in Nordic countries and the US have likewise been $1 \mathrm{~B}$. Genetic similarity between these and the BC HAV $1 B$ strain was high: $98.7 \%$ with the Danish, $98.6 \%$ with the Norwegian and $99.2 \%$ with the US strains. Although based on 373 nucleotides from the VP1-2A region, there was no bootstrap support for phylogenetic relatedness (Figure 3).

The very low number of cases in this outbreak, despite widespread purchase and probable consumption of the product, led to challenges in determining the appropriate response, both in terms of public messaging and offering vaccination. Approximately 3,000 vaccines were given in response to exposure to the food service worker and between 300 and 340 vaccines across the province in response to the alert for the implicated product. One confirmed case consumed the product after the recall had been issued, suggesting incomplete penetration of public health messaging. While the number of annual reported cases of hepatitis $A$ is low in BC, seroprevalence of anti-HAV antibodies is also low [28], leading to the ongoing potential for outbreaks.

Fraser Health Environmental Health Investigation Team Jason Stone, Steven Trerise, Shendra Brisdon, Ken Louie, Rod Asplin, Andrea Stiller, Tara Abraham, Inderjeet Singh Gill and George Rice.

\section{Acknowledgments}

Thanks to Elsie Grudeski (Public Health Agency of Canada), Eliza Yue (Canadian Food Inspection Agency), Marsha Taylor (BC Centre for Disease Control), Fraser Health Authority, Vancouver Coastal Health Authority and Vancouver Island Health Authority.

The authors would also like to acknowledge the work of Sunny Mak, BC Centre for Disease Control Medical Geographer, in creating the map in Figure 1.

Conflict of interest

None declared.

\section{Authors' contributions}

$\mathrm{HS}, \mathrm{BH}$ and $\mathrm{AB}$ led the epidemiological investigations at the local and provincial level. GE and the Fraser Health Environmental Health Investigation Team interviewed the initial cases and performed an environmental investigation. MK drafted the manuscript. $A A$ was in charge of the laboratory genotyping. $\mathrm{HS}, \mathrm{AA}, \mathrm{BH}, \mathrm{JAB}$ and $\mathrm{GE}$ critically reviewed the draft manuscript and provided substantive input. All authors contributed to the epidemiological investigation and writing of the manuscript and approved the final version.

\section{References}

1. British Columbia Centre for Disease Control (BCCDC) Communicable disease control. Hepatitis A. August 2008. Vancouver: BCCDC. [Accessed 5 May 2014]. Available from: http://www.bccdc.ca/NR/rdonlyres/92CF634C-23D6-4B49B6BA-98B83C77FFoo/o/HepA_August_2008.pdf

2. British Columbia Centre for Disease Control (BCCDC). 2011 Annual summary of reportable diseases. Vancouver: BCCDC. [Accessed 15 Apr 2014]. Available at: http://www.bccdc.ca/util/ about/annreport/default.htm

3. British Columbia Centre for Disease Control (BCCDC). Hepatitis $A$ in British Columbia, 2010 - 2011. Vancouver: BCCDC. [Accessed 15 Apr 2014]. Available from: http://www.bccdc.ca/ NR/rdonlyres/BAFDED8C-77EA-4493-A3A9-6AD7483A65D6/o/ HepatitisAUpdateBC20102011.pdf

4. Heymann DL. Hepatitis, viral. In: Control of communicable diseases manual. 19th ed. Washington, DC: American Public Health Association; 2008. p. 278-84.

5. Hutin YJ, Pool V, Cramer EH, Nainan OV, Weth J, Williams IT, et al. A multistate outbreak of hepatitis A. National hepatitis A investigation team. N Engl J Med. 1999;340(8):595-602. http://dx.doi.org/10.1056/NEJM199902253400802

6. Tricco AC, Pham B, Duval B, De Serres G, Gilca V, Vrbova L, et al. A review of interventions triggered by hepatitis $A$ infected food-handlers in Canada. BMC Health Serv Res. 2006;6:157. http://dx.doi.org/10.1186/1472-6963-6-157

7. Wheeler C, Vogt TM, Armstrong GL, Vaughan G, Weltman A, Nainan OV, et al. An outbreak of hepatitis A associated with green onions. N Engl J Med. 2005;353(9):890-7. http://dx.doi.org/10.1056/NEJMoa050855

8. Amon JJ, Devasia R, Xia G, Nainan OV, Hall S, Lawson B, et al. Molecular epidemiology of foodborne hepatitis A outbreaks in the United States, 2003. J Infect Dis. 2005;192(8):1323-30. http://dx.doi.org/10.1086/462425

9. Calder L, Simmons G, Thornley C, Taylor P, Pritchard K, Greening G, Bishop J, et al. An outbreak of hepatitis A 
associated with consumption of raw blueberries. Epidemiol Infect. 2003;131(1):745-51.

http://dx.doi.org/10.1017/So950268803008586

10. Niu MT, Polish LB, Robertson BH, Khanna BK, Woodruff BA, Shapiro CN, et al. Multistate outbreak of hepatitis A associated with frozen strawberries. J Infect Dis. 1992;166(3):518-24. http://dx.doi.org/10.1093/infdis/166.3.518

11. Carvalho C, Thomas HL, Balogun K, et al. A possible outbreak of hepatitis A associated with semi-dried tomatoes, England, July-November 2011. Euro Surveill. 2012;17(6):pii=20083.

12. Coudray C, Merle G, Martin-Latil S, Guillier L, , Perelle S. Comparison of two extraction methods for the detection of hepatitis $A$ virus in lettuces using the murine norovirus as a process control. J Virol Methods. 2013;193(1):96-102. http://dx.doi.org/10.1016/j.jviromet.2013.05.003

13. Hida K, Kulka M, Papafragkou E. Development of a rapid total nucleic acid extraction method for the isolation of hepatitis $A$ virus from fresh produce. Int J Food Microbiol. 2013;161(3):14350 .

http://dx.doi.org/10.1016/j.ijfoodmicro.2012.12.007

14. Chironna M, Lopalco P, Prato R, Germinario C, Barbuti S, Quarto M. J Clin Microbiol. 2004;42(6):2825-8. http://dx.doi.org/10.1128/JCM.42.6.2825-2828.2004

15. Tamura K, Stecher G, Peterson D, Filipski A, Kumar S. MEGA6: Molecular Evolutionary Genetics Analysis version 6.0. Mol Biol Evol. 2013:30(12):2725-9. http://dx.doi.org/10.1093/molbev/mst197

16. Statistics Canada. Household size, by province and territory (2011 census) (Manitoba, Saskatchewan, Alberta, British Columbia). Ottawa: Statistics Canada. [Accessed 9 Dec 2013]. Available from: http://www.statcan.gc.ca/tables-tableaux/ sum-som/lo1/csto1/famil53c-eng.htm

17. Statistics Canada. Population and dwelling counts, for Canada, provinces and territories, 2011 and 2006 censuses. Ottawa: Statistics Canada. [Accessed 9 Dec 2013]. Available from: http://www12.statcan.gc.ca/census-recensement/2011/dp-pd/ $\mathrm{hlt}$-fst/pd-pl/Table-Tableau.cfm?LANG=Eng \&T=101\&S=50\&O=A

18. British Columbia Centre for Disease Control (BCCDC). Pomeberry frozen berries may contain hepatitis $A$. Vancouver: BCCDC; 5 April 2012. Available from: http:// www.bccdc.ca/resourcematerials/newsandalerts/ healthalerts/2012 HealthAlerts/Pomeberry+frozen+berries+ma y+contain+hepatitis+A.htm

19. Canadian Food Inspection Agency (CIFA). The Canadian food safety system: food recalls. Ottawa: CIFA. [Accessed $222 \mathrm{Apr}$ 2014]. Available from: http://www.inspection.gc.ca/about-thecfia/newsroom/food-safety-system/food-recalls/eng/13322065 99275/1332207914673

20. Canadian Food Inspection Agency (CIFA). Health Hazard Alert - Certain Western Family brand Pomeberry Blend berries may contain hepatitis A virus. 5 April 2012. Ottawa: CIFA. [Accessed 15 Apr 2013]. Available from: http://www.inspection.gc.ca/ english/corpaffr/recarapp/2012/20120405de.shtml

21. Health Canada. Weight of evidence: factors to consider for appropriate and timely action in a foodborne illness outbreak investigation. Ottawa: Health Canada; Jan 2011. Available from: http://www.hc-sc.gc.ca/fn-an/pubs/securit/2011-food-illnessoutbreak-eclosion-malad-ailments/index-eng.php

22. Gillesberg Lassen S, Soborg B, Midgley SE, Steens A, Vold L, Stene-Johansen K, et al. Ongoing multi-strain food-borne hepatitis A outbreak with frozen berries as suspected vehicle: four Nordic countries affected, October 2012 to April 2013. Euro Surveill. 2013;18(17):pii=20467.

23. Nordic outbreak investigation team. Joint analysis by the Nordic countries of a hepatitis A outbreak, October 2012 to June 2013: frozen strawberries suspected. Euro Surveill. 2013;18(27):pii=20520.

24. Centers for Disease Control and Prevention (CDC). Multistate outbreak of Hepatitis A infections linked to pomegranate seeds from Turkey (final update). Atlanta, GA: CDC; 28 Oct 2013. Available from: http://www.cdc.gov/hepatitis/Outbreaks/2013/ A1b-03-31/

25. Shah L, MacDougall L, Ellis A, Ong C, Shyng S, LeBlanc L, et al. Challenges of investigating community outbreaks of cyclosporiasis, British Columbia, Canada. Emerg Infect Dis. 2009;15(8):1286-8.

http://dx.doi.org/10.3201/eid1508.081585

26. Petrignani $M$, Verhoef $L$, van Hunen $R$, van Steenbergen J, Boxman I, Ober HJ, et al. A possible foodborne outbreak of hepatitis $A$ in the Netherlands, January-February 2010. Euro Surveill. 2010;15(11): pii=19512.

27. Andonov A, Grudeski E, Morbey M. Molecular epidemiology of hepatitis A virus (HAV) in Canada. Proceedings of the Canadian Association for Clinical Microbiology and Infectious Diseases (CACMID) 72nd Conjoint Meeting on Infectious Diseases; 2004 Nov 7-10; Regina, Saskatchewan. Abstract, p. 44.
28. Pham B, Duval B, De Serres G, Gilca V, Tricco AC, Ochnio J, et al. Seroprevalence of hepatitis A infection in a low endemicity country: a systematic review. BMC Infect Dis. 2005;5:56. http://dx.doi.org/10.1186/1471-2334-5-56

29. Island Health. Hepatitis A immunizations available To Fairway Markets Quadra location employees and members of the public. Victoria: Island Health; 31 Mar 2012. Available from: http://www.viha.ca/about_viha/news/news_releases/hep_a_ nr_march12.htm 